\title{
UNIVERSIDADE, CULTURA E CIENTICIFIZAÇÃO DAS SOCIEDADES MODERNAS
}

\begin{tabular}{|c|c|}
\hline $\begin{array}{c}\text { UNIVERSITY, CULTURE AND } \\
\text { CIENTICIFIZAÇÃO COMPANY MODERN }\end{array}$ & \\
\hline $\begin{array}{l}\text { UNIVERSIDAD, CULTURA Y CIENTIFICIZACIÓN } \\
\text { DE LAS SOCIEDADES MODERNAS }\end{array}$ & \\
\hline & António Cachapuz \\
\hline $\begin{array}{l}\text { RESUMO } \\
\text { Aborda-se a desvalorização actual da formação cultural na Universidade. Tendo em co } \\
\text { e implicações dos processos de cientificização das sociedades modernas, aprofunda-se } \\
\text { cultura científica. Defende-se uma visão humanista de ciência, ciência cidadã, que d } \\
\text { desenvolvimento da cultura científica nas sociedades modernas que se querem a } \\
\text { apresentam-se sugestões de como melhorar tal desenvolvimento. }\end{array}$ & $\begin{array}{l}\text { a a natureza, amplitude } \\
\text { argumento no caso da } \\
\text { e guiar a construção e } \\
\text { rtas e democráticas e }\end{array}$ \\
\hline
\end{tabular}

PALAVRAS-CHAVE: Universidade. Cultura científica. Humanismo.

\begin{abstract}
It deals with the current devaluation of cultural education at the University. Taking into account the nature, extent and implications of scientification processes of modern societies, deepens the argument in the case of scientific culture. It defends a humanistic view of science, citizen science, which must guide the construction and development of scientific culture in modern societies that want open and democratic and are suggestions on how to improve such development.
\end{abstract}

KEYWORDS: University. Scientific culture. Humanism.

\section{RESUMEN}

Se aborda la desvalorización actual de la formación cultural en la Universidad. Teniendo en cuenta la naturaleza, amplitud e implicaciones de los procesos de cientificización de las sociedades modernas, se profundiza el argumento en el caso de la cultura científica. Se defiende una visión humanista de ciencia, ciencia ciudadana, que debe guiar la construcción y desarrollo de la cultura científica en las sociedades modernas que se quieren abiertas y democráticas y se presentan sugerencias de cómo mejorar dicho desarrollo.

PALABRAS CLAVE: Universidad. Cultura científica. Humanismo.

\footnotetext{
${ }^{1}$ Universidade de Aveiro/CIDTFF. Portugal. E-mail: cachapuz@ua.pt

Recebido em: 25/07/2016 - Aceito em: 03/09/2016.
} 


\section{DA UNIVERSIDADE}

Pelo papel que a Universidade assume de incubadora de potenciais "elites" que assumirão no decurso da sua vida profissional posições de impacto social e de $\operatorname{poder}^{2}$, é importante um olhar atento e não ingénuo sobre as questões recorrentes da sua missão no quadro de sociedades modernas que se querem abertas e democráticas.

A questão é da ordem das políticas e, no fundo, tem a ver com o papel que entendemos ser o da Universidade no que respeita aos processos de construção cultural e social, o "para quê" e "para quem" da sua razão de ser. O momento é pertinente, sobretudo desde que a deriva neoliberal ancorada no New Public Management se instalou na Universidade (e não só), fragilizando a visão humanista que permeou a sua origem Humboltiana ${ }^{3}$. "A crise das ideias permeou todos os espaços da vida social, incluindo as Universidades" (ZABALZA, apud BENTO, 2014, p.79). Ortega y Gasset tinha avisado: "Comparada com a Universidade medieval, a Universidade contemporânea complicou enormemente o ensino das profissões que aquela em germe proporcionava e adicionou-se a investigação, retirando quase por completo o ensino ou a transmissão da cultura. O que foi evidentemente uma barbaridade...o novo bárbaro, é, na verdade mais sábio que nunca, mas o mais inculto também, o médico, o advogado, o homem de ciência dos nossos dias" (GASSET, 1946, p.33). Mais perto de nós, Bento (2014, p. 60) refere que a Universidade não deve ficar à margem do tempo mas que a sua reforma também não deve servir fins espúrios: "Certamente é desejável que a Universidade... nunca se dê por concluída ou satisfeita. Em igual medida é desejável que não se acomode ...que não se vergue às forças que visam decretar o fim da sua visão humanista".

\section{O que é que falta?}

"Em nosso parecer, o ensino universitário implica a integração de três funções: transmissão da cultura; ensino dedicado às profissões liberais; investigação científica e formação de novos homens de ciência" (GASSET, 1946, p. 39). Passo por cima de alguns detalhes mais controversos desta argumentação para sublinhar que o que falta é a integração harmoniosa das três funções descritas com prejuízo claro da primeira delas.

De entre as funções históricas da Universidade, a da formação para a cultura e para os valores tem estado sobretudo ausente, invariavelmente relegada para a auto - formação. Não se trata aqui da cultura das redes virtuais, a "Cultura Mundo" de que fala Gilles Lipovestky

\footnotetext{
${ }^{2}$ Assumo aqui a linha de Michel Foucault (1972), sobre o conceito de Poder em que este não deve restringir-se à visão restrita dos meios jurídico - institucionais (tipicamente o Estado e seu aparelho político/administrativo). Mas sim estender-se a uma análise dos modos concretos como o Poder se desdobra em diferentes níveis e sob diferentes formas da sociedade (directores de serviços, chefes de secção, hierarquias universitárias etc...).
}

\footnotetext{
${ }^{3}$ Neave lembra que foi com a Concordata de Wilhem von Humbolt, primeira modernização da universidade europeia, que a universidade foi colocada ao serviço do Estado, como serviço público, e não como corporação privada (2008, p.49).
} 
(2014), que se confunde com o divertimento e prazer, em que é a tecnologia que passa a legitimar o conteúdo e denunciada por Pereira $(2016,52)$ : "não é preciso saber; basta estar conectado". A cultura de que se fala aqui, é a qualidade que ajuda o indivíduo, e/ou grupo e/ou a sociedade a dar sentido, coerência e orientação ao conhecimento, lidar com a mudança e dela formar uma representação coerente. Para Vargas Losa (2012), "os seus produtos pretendem transcender o tempo presente...e não ser fabricados para ser consumidos nesse instante e desaparecer como os biscoitos ou pipocas" (p.28). De modo mais filosófico, segundo Humberto Eco, tornar o infinito compreensível (ECO, 2015). Embora com honrosas excepções, em particular no âmbito das Artes e das Humanidades, não é preciso procurar muito nos currículos universitários um pouco por todo o mundo para corroborar o argumento, em particular, a omissão da componente ética e a confusão entre educação e instrução. A procura da unidade do saber, uma das exigências maiores da cultura, está ausente. A lacuna estende-se por indução ao que o sistema valoriza em termos de "modelo" de docente universitário, embora a formação dos estudantes seja inseparável da formação dos seus professores. Na verdade, o retrato robot do perfil do docente universitário valoriza sobretudo a vertente de investigação, publicações em revistas de elevado impacto, capacidade de obter financiamento externo para projectos e... sem grandes problemas com os alunos. E a socialização dos jovens docentes à entrada da universidade é, invariavelmente feita segundo estas linhas de força que perduram ao longo da sua formação. Há que combater um tal estado de coisas. "A atitude da formação vive de uma aposta audaciosa em torno do Homem e do sonho da aventura da sua promoção e dignificação. A sociedade contemporânea atravessa actualmente um período de dissociação política e cultural que irá suscitar um renascimento social de que ninguém, até ao presente, consegue medir nem a forma nem a envergadura. A antiga modernidade continha uma cidadania simples. A nova é complexa, devido ao alargamento dos campos da cidadania cívica a outras escalas” (REIMÃO, 2001, p. 21).

A desvalorização da formação cultural, incluindo a formação para os valores, é particularmente gravosa no caso das formações no âmbito das Ciências e Tecnologias ${ }^{4}$ tendo em conta a natureza, amplitude e implicações dos processos de cientificização das sociedades modernas (BECK, 2008). "A Universidade, sendo um património público que existe para melhorar a vida das pessoas e ajudar a construir sociedades justas e livres...não deve aceitar o determinismo tecnológico e/ou económico como verdade auto evidente (SOBRINHO, apud BENTO 2014, p. 20).

Os primeiros sinais de alarme não são de agora. De acordo com o Livro Branco “Ensinar e Aprender” da Comissão Europeia (1995, p. 28)

[...] para o exercício a cidadania numa sociedade europeia, pluricultural, e democrática, é importante sublinhar o papel da cultura científica suficiente (não redutível à cultura matemática) para o bom exercício da democracia. As nossas democracias funcionam segundo regras de decisão maioritária sobre grandes problemas que, devido à sua complexidade, requerem cada vez mais cultura. São

\footnotetext{
${ }^{4}$ Tecnociência, termo aqui usado, tendo em conta que a divisão entre Ciência e Tecnologia nas sociedades modernas não é realista. Pressupõe um estereótipo de inovação linear ultrapassado (ZIMAN, 1999).

\begin{tabular}{l|l|l|l|l|l|l} 
(C) Rev. Inter. Educ. Sup. & Campinas, SP & v.2 & n.2 & p.229-240 & maio/ago. 2016 & ISSN 2446-9424
\end{tabular}
} 
nomeadamente problemas ambientais ou éticos que não poderão ser vantajosamente ultrapassados se não formarmos jovens dotados de sentido científico. Não se trata naturalmente de transformar cada cidadão num perito científico mas de lhe permitir desempenhar um papel esclarecido (p. ex., como consumidor) e de compreender o sentido geral e as implicações sociais dos debates entre peritos.

Caro (2001, p. 30) refere que, "a modernidade aposta na cooperação entre a ciência, a arte e a ética. Hoje o que se passa é um atrito entre a ciência e a ética. E esse atrito surgiu justamente quando a ciência começou a trabalhar com matéria viva".

Parte do problema tem a ver com os sistemas de ensino terem estado demasiado focados em como aumentar o conhecimento científico (ideal enciclopédico) e não tanto para que é que serve a cultura científica como instrumento de realização pessoal, compreensão do mundo e, sublinhe-se, de intervenção social. Também no âmbito das políticas públicas, não é claro quem decide o quê. Sclove (1995, p. 240) chama a atenção para algumas distorções:

De uma forma recorrente poderosos agentes políticos (políticos profissionais,
dirigentes de corporações...) apoiados por equipas de peritos técnicos, têm
ritualmente debatido os custos económicos e suas consequências, implicações para
a segurança militar, riscos para a saúde e segurança ou impactos ambientais, da
actual panóplia de desenvolvimentos tecnológicos. As questões abordadas não são
irrelevantes, mas este sistema de discurso público e de decisão é no entanto
inadequado porque exclui os cidadãos das verdadeiras decisões atribuindo-lhes um
papel trivial; em geral, levanta questões somente muito depois das decisões
importantes terem sido já tomadas; dirige a atenção para fins focais com prejuízo de
importantes aspectos culturais e consequências sociais não focais; deixa por
esclarecer as implicações democráticas.

Importante é assegurar que a construção cultural que está no DNA da Universidade sirva um projecto estratégico da cidadania ${ }^{5}$ ancorada em direitos de terceira geração, valorizando o factor humano, o conhecimento, uma ética de solidariedade, a participação na resolução dos nossos problemas não reduzida à escolha de soluções possíveis previamente propostas ou mera representação democrática de ordem formal cujos limites são bem conhecidos. Uma cidadania que se não restringe ao imediato local nem sequer às fronteiras dos Estados Nação, já que a solidariedade é aí um eixo actuante: Chernobyl não se limitou aos céus da Ucrânia; o derrame do Prestige não se ficou pelas praias da Galícia; a desflorestação da Amazónia não atinge só o Brasil. Essa é a mudança que precisamos e que vale a pena defender.

Estas as preocupações que me trazem aqui. O que se pretende é defender uma visão humanista de ciência que deve guiar a construção e desenvolvimento da cultura científica nas sociedades modernas que se querem abertas e democráticas e acentuar a responsabilidade social da Universidade nesse processo. Cultura científica, entendida aqui como a qualidade que dá sentido e orientação ao conhecimento científico (estrito senso), que não se restringe à racionalidade instrumental, que o questiona, que se coloca ao serviço de uma cidadania

${ }^{5}$ Sobre a construção historicamente situada de cidadania ver Santos, E. (2005).

\begin{tabular}{l|l|l|l|l|l|}
\hline (c) Rev. Inter. Educ. Sup. & Campinas, SP & v.2 & n.2 & p.229-240 & maio/ago. 2016
\end{tabular} 
responsável. Em suma, que abre um outro olhar de compreensão sobre o mundo na sua complexidade, diversidade e mudança.

No que se segue, num primeiro tempo, apresentam-se de modo sumário perspectivas correntes de ciência de modo a elucidar aspectos essenciais sobre o que as une e o que as separa e qual a opção tomada por uma visão humanista da mesma. Num segundo tempo, em linha com a visão de ciência defendida, apresentam-se reflexões e sugestões sobre o que podem ser bons pontos de partida para melhorar a cultura científica envolvendo outras políticas de formação e de ciência, em particular: defender uma imagem de ciência mais próxima das suas próprias dinâmicas de desenvolvimento; socialização do saber científico aproximando as comunidades científicas das comunidades educativas; necessidade de valorizar uma educação científica de raiz CTS; formação de professores; criar critérios de qualidade no que respeita à divulgação científica a quem tem acesso a grandes audiências públicas (jornalistas, políticos...); valorização do que une as ciências sociais e humanidades às ciências experimentais na interpretação do mundo ou ainda, reorientar o processo de decisão tecnocrático prevalecente para linhas mais democráticas.

\section{DOS OLHARES SOBRE A CIÊNCIA}

É diverso o modo como se concebe a ciência como dispositivo tentativo de representação unificada e coerente do mundo. De modo sumário, podem-se traçar três visões dominantes que permeiam o olhar sobre a ciência moderna (para desenvolvimentos ver p. ex., BECK, 2008; GARCIA et al. 1996; SANTOS, E. 2005; SOLBES, 1999).

O primeiro olhar, considera que a ciência e a tecnologia são formas defeituosas de acção humana e socialmente desestabilizadoras. É uma visão crítica e, segundo Santos, B (1989) ancorado no pessimismo de Heidegger para quem ciência e tecnologia correspondem a uma compreensão dogmática do ser. Ou seja, é um olhar que basicamente considera a ciência como perversa, já que o conhecimento científico é contrário à felicidade humana. De acordo com Solbes (1999), esta visão revela-se ao questionar as vantagens da ciência (medicina, transportes, agricultura...) se acompanhadas de bombas atómicas, contaminação, degradação ambiental, etc...Ideologicamente situa o nascimento da ciência moderna com o capitalismo, partilhando com ele o desejo de dominar, explorar e manipular a natureza e o Homem. Historicamente aparece como reacção radical ao cientismo. Considera como ingénua a visão do CUDOS (Comunalismo; Universalismo; Desinteresse, Originalidade e Cepticismo) como DNA da prática científica tal como formulado por Merton nos anos 40. Um dos alvos preferidos da crítica é o suposto Desinteresse (a ciência pela ciência), contrapondo exemplos recorrentes de secretismo da investigação, busca de prestígio ou recompensas materiais. Para Ziman (1999) tais desvios da ciência têm a ver com as dinâmicas de passagem da ciência académica (em que a principal recompensa é o reconhecimento social) para um modo de produção de ciência industrial (em que a recompensa já é promoção e benefícios de ordem material). 
A segunda visão de ciência é a dominante na comunidade dos cientistas e publicamente valorizada. Em maior ou menor extensão é marcada pela epistemologia positivista e leitura restrita do conhecimento científico de que a perspectiva STEM (Science, Technology, Engineering, Mathematics) é um exemplo recente (ver relatório anual em Petersen, 2015). Considera a ciência como forma verdadeira de conhecimento, para alguns a única (visão dogmática), para outros tentativa e dinâmica, e socialmente benéfica. "Quem vive numa sociedade moderna e não gosta ou não se aproxima da ciência, não convive bem com ela, é moderno apenas em parte. É alguém que entra no futuro em marcha - atrás" (CARAÇA, 2007, p. 30).

É um posicionamento que assume quase sempre uma visão antropocêntrica em que o Homem conquista e controla a natureza. No essencial, cultura científica resume-se ao conhecimento científico. Estabelece uma clara distinção entre ciência e tecnologia, reconhecendo excessos sobretudo nas suas aplicações tecnológicas e defende, no essencial, a neutralidade da ciência. Para alguns autores (ZIMAN, 1999), esta distinção entre ciência e tecnologia não tem sentido na ciência moderna pois tem por pressuposto um estereótipo de modelo linear de inovação que está ultrapassado (ver uso de tecnociência). Segundo este autor, esta visão dualista ignora preocupações sociais, inventa uma distinção artificial entre "ciência tecnologicamente orientada" e "tecnologia cientificamente baseada" de forma a que a investigação "pura" tem consequências práticas de que não tem responsabilidade moral. É uma visão de ciência contestada por vários autores, sobretudo sociólogos (p. ex., Edgar Morin, Boaventura Santos, Urlich Beck, entre outros).

A terceira visão de ciência é claramente marcada por preocupações humanistas, uma ciência para a cidadania, socialmente comprometida e em que há alterações profundas nas relações entre, ciência, tecnologia e sociedade numa abordagem interdisciplinar, uma abordagem CTS. Nesta visão, a "interpenetração dinâmica da ciência e da cultura revelou-se como um factor incontornável do conhecimento no século XXI" (NERY, 2016, p. 25). Ao contrário da visão anterior, a unidade entre a ciência e a tecnologia é uma característica que distingue a ciência contemporânea da ciência tradicional. "Tal unidade modifica a nossa interpretação acerca do mundo e dos acontecimentos que nele ocorrem, confrontando-nos com a forma como nele nos inserimos, vivemos e identificamos" (PRAIA e CACHAPUZ, 2005, p.174).

Há novos actores envolvidos:

a ciência torna-se cada vez mais necessária mas cada vez menos suficiente na elaboração de uma definição socialmente estabelecida da verdade. Nesta nova configuração, a relação entre a ciência e o exterior alterou-se e os destinatários e utilizadores da ciência na sociedade têm agora novas possibilidades de influência e de acção nos processos de produção e da utilização dos resultados científicos (BECK, 2008, p. 344).

É o que ele chama de "cientificização reflexiva" em contraponto com "cientificização simples" em que as dinâmicas se alimentavam da oposição entre peritos e profanos (ib.). A 
crescente influência social dos movimentos ambientalistas, da defesa do património arquitectónico ou no campo da bioética, entre outros, ilustram o argumento.

Sob o ponto de vista epistémico, ao envolver uma visão externalista e socialmente comprometida do conhecimento, rompe com o legado positivista e é um passo em frente em relação ao STEM. Trata-se de uma nova abordagem de forma a dar sentido, unidade e coerência a saberes e experiências dispersas no quadro de uma leitura humanista, que "implica fertilizar o saber científico com outros saberes, derrubar os obstáculos epistemológicos que impedem a construção de um novo objecto de saber e a sua necessária interacção com o sujeito e estabelecer bases epistemológicas adequadas para pensar articulações Ciência/Tecnologia/Sociedade" (SANTOS, E., 2005, p. 146). E a mesma autora refere que "é necessário "civilizar a ciência" e "cientifizar" a cidadania, como condições para potenciar uma ciência menos arrogante e uma cidadania mais democrática" (p.14).

O "para quê" e "para quem" da ciência ficam mais claros no quadro da visão CTS socialmente comprometida. Há novos actores envolvidos e novas fertilizações de saberes. O próprio objecto de estudo também se alargou: “...deixou de ser somente a natureza, o Homem e a sociedade, mas cada vez mais a ciência, ela mesma, os seus produtos, os seus efeitos e os seus erros" (SANTOS E, 2005, p. 347). Nas suas linhas mestras, esta é a visão de ciência que aqui se defende e que deve enformar a construção da cultura científica e nortear as condições do seu desenvolvimento.

\section{DAS CONDIÇÕES DE MUDANÇA}

A intenção é apontar caminhos possíveis de valorização da cultura científica no quadro de uma visão humanista da ciência mais do que criar uma agenda. Como é sabido, o campo de actuação da visão CTS, no essencial, desdobra-se a nível da investigação académica, das políticas públicas e da formação/educação científica. É sobre as duas últimas que a seguir se apresentam considerações, permitindo-me aprofundar algumas delas que sobre o tema já defendi (CACHAPUZ, 2011; CACHAPUZ, 2016) dada a sua pertinência para este trabalho.

\section{Condições da ordem da formação}

É necessário compreender que a imagem pública dominante de Ciência (ver acima) continua a não seduzir muitos jovens. Beck (2008) põe o dedo na ferida comentando a imagem externa de infalibilidade em contradição com a própria construção da ciência. "Não são os desaires mas sim os sucessos da ciência que a destronaram" (p. 356). E acrescenta: "O modelo de cientificização simples repousa sobre a hipótese ingénua segundo a qual o cepticismo metódico das ciências poderia ser institucionalizado e limitado aos objectos da ciência" (ib.). Ou seja, apresentar-se-ia como um dogma em direcção ao exterior o que no interior seria objecto de dúvidas e questionamentos. Só que a imagem da ciência como um 
dogma, não aproxima adeptos. O modo como resolver esta ambiguidade passa seguramente por uma educação científica de qualidade tendo em vista o exercício efectivo da cidadania, envolvendo a compreensão da evolução dos contextos sociais e controvérsias históricas, metodologias de trabalho abertas e de sentido crítico que permitam explicar, comentar, compreender e questionar a ciência que temos, em suma uma visão CTS.

A procura da unidade do saber é uma das exigências maiores da cultura. Um dos traços marcantes da organização das formações universitárias é a falta de espaços onde se possam fertilizar saberes de áreas diversas. Algumas experiências de sucesso sugerem a inclusão nos currículos formais de espaços interdisciplinares; ou a abertura multidisciplinar a outras áreas de formação (optativas ou não), caso paradigmático do MIT onde todos os alunos da graduação têm de frequentar oito disciplinas nas áreas da literatura, música, história economia, ou seja, cerca de $25 \%$ de todo o percurso académico, já que "as questões da engenharia e da ciência estão sempre mergulhadas em realidades humanas mais amplas. Por isso, os nossos estudantes precisam também de adquirir um conhecimento aprofundado das complexidades humanas bem como a fluência nas poderosas formas de pensamento e de criatividade cultivada pelas humanidades" (Deborah FITZGERALD, directora de estudos do MIT, apud NERY, 2016, p.26); importa ainda valorizar metodologias abertas de trabalho (p. ex., do tipo PBL) envolvendo, mais do que a aprendizagem de conceitos isolados, a resolução de situações problema devidamente contextualizadas e elucidar o sentido do que se aprende. Em qualquer dos casos, o que está em jogo são decisões estratégicas de ordem das políticas de formação sobre o sentido e papel do conhecimento e da cultura científica no quadro de uma visão CTS. Na Europa, a lógica de Bolonha ao limitar os tempos de formação, não só não resolveu problemas existentes como até os agravou. Além da perda de identidade dos diferentes graus, articulação precária entre ciclos de formação ou desvalorização da iniciação à investigação recorrentemente referidos na literatura, a diminuição dos tempos de formação induz metodologias de trabalho de índole transmissiva de qualidade discutível. Também aí há algo que importa refazer. O ensino no quadro de uma pedagogia crítica tem tudo para se tornar mais sedutor. Por exemplo, é importante que os estudantes universitários possam conhecer, através de estudos de caso ou seminários temáticos, a história escondida da ciência, afastando-se da visão heroica dominante e aprofundando as controvérsias não só epistemológicas, mas também os contextos sociais em que o processo de descoberta se inseriu.

Conteúdos e metodologias de trabalho são dispositivos importantes de mudança. Mas não chega. O dispositivo chave é assegurar a formação interdisciplinar dos profissionais de ciência, cientistas, investigadores, engenheiros, professores (universitários ou não) etc...dado que, de algum modo, estão/estarão em posições chave para influenciar as dinâmicas de evolução do desenvolvimento científico/tecnológico e sua orientação segundo padrões de abertura a uma ética de responsabilidade e de solidariedade, tolerância epistemológica e preocupações de ordem social. 
Refira-se ainda, por respeito por quem tem a responsabilidade de organizar e gerir no terreno os sistemas de formação, que os políticos devem preocupar - se mais com decisões a médio e longo prazo, nem sempre coincidentes com os ciclos políticos. Ou seja, serem eticamente coerentes com as suas responsabilidades de serviço público. Em Portugal, desde a revolução do 25 de Abril de 1974, a média de vigência dos ministros da educação é de cerca de 1,5 anos. Pior ainda, é a necessidade de, mesmo assim, fazerem a sua reformazinha. É imoral. Se há algo que os sistemas de ensino necessitem é de estabilidade e previsibilidade para levarem as reformas em curso até ao fim, após avaliações qualificadas das anteriores

\section{Condições da ordem da ciência}

"Todos os empreendimentos colectivos exigem confiança. Dos jogos infantis às instituições sociais complexas os homens não podem trabalhar juntos a menos que suspendam a sua desconfiança mútua" (JUDT, 2010, p.74). A ciência é um desses empreendimentos. É necessário uma maior transparência do discurso político. A experiência mostra que não é de esperar que tal transparência seja da iniciativa do poder político. Por isso mesmo é um acto de cidadania ajudar a desocultá-lo. Jasanoff (2007) afirma a obrigação de, em democracia, o poder político ter de esclarecer os critérios e sentido das suas decisões. Não faltam exemplos, desde a incineração de resíduos industriais, necessidade de rotulagem de alimentos transgénicos, acesso/desvio e limpeza de cursos de água, medidas para minimizar a poluição atmosférica, etc (ver p. ex., HARKER, 2015). Os interlocutores adequados devem ser as associações de consumidores, moradores, usuários com propósitos comuns e não cada cidadão individualmente considerado. Shamos (1995) tinha provavelmente razão ao considerar a literacia científica universal (itálico meu) como um mito, mas essa não é a única maneira de participar em sociedade. Nesse processo, os media desempenham um papel essencial já que a ignorância e percentagem de audiências dos media são tóxicos para o desenvolvimento da cultura científica. "A distância entre o que os cientistas sabem e o que o público entende é uma das maiores ameaças a uma política pública e científica lúcida. É necessário melhorar a difusão da ciência pelos meios de comunicação de massa" (MAYOR, 1998, p. 132). Canais temáticos televisivos são bons exemplos, mas não chegam. O mesmo autor refere que é necessário melhorar a formação dos jornalistas e do próprio formato de difusão já que a atenção dos media incide sobretudo sobre questões de interesse imediato, quase sempre não compatíveis com dinâmicas da ciência que se arrastam no tempo e que, por isso mesmo, são desvalorizadas pelos media.

Finalmente, o conteúdo e os objectivos de programas internacionais de ciência devem ser reorientados de forma a melhor servir necessidades humanas básicas a toda a humanidade e não só a uns poucos privilegiados (FORTI, 1998, p.20). Em síntese, na concepção de tais programas, ter presente uma matriz dos Direitos Humanos. Importa criar orgãos de cooperação internacional (à imagem da UNESCO) de forma a favorecer países menos desenvolvidos no seu desenvolvimento científico e tendo em vista resolver sustentadamente, e não só de forma local e temporária, problemas de qualidade de vida e do bem estar dos seus cidadãos (MAYOR, 1998, p.126).

\begin{tabular}{l|l|l|l|l|l|l} 
(C) Rev. Inter. Educ. Sup. & Campinas, SP & v.2 & n.2 & p.229-240 & maio/ago. 2016 & ISSN 2446-9424
\end{tabular}


A falta de concretização adequada de várias destas condições, quase duas décadas depois, revela a complexidade das articulações entre a ciência/tecnologia e políticas públicas. Apela também à vigilância que é necessário manter sobre o desenvolvimento das mesmas.

\section{NOTAS FINAIS}

"Um médico que só sabe ser médico nem médico sabe ser", esta a frase da autoria de Abel Salazar com que deparei na minha juventude no frontispício da antiga Escola Médica/Faculdade de Medicina da Universidade do Porto. Por alguma razão esta frase perdurou desde então na minha memória. Só mais tarde compreendi o seu verdadeiro sentido e tomei conhecimento da figura insigne de Abel Salazar: médico, cientista de renome, artista (desenhador), pedagogo e democrata engajado, intelectual de corpo inteiro na esteira de Gramsci (seu contemporâneo) e que, por isso mesmo, como vários outros, tinha sido expulso da Academia pelo ditador Salazar (por ironia da vida com ele partilhando casuisticamente o mesmo nome de família). A história está repleta de exemplos de cientistas, e não só, que, como Abel Salazar, em confronto com autoridades (políticas e religiosas) pagaram caro seus actos de cidadania (ver por exemplo, FORTI,1998). O que o cientista Abel Salazar nos deixou foi um exemplo de formação humanista, de ética cidadã, de formação para os valores da cultura e da cidadania e que deve estar presente nos homens e mulheres de ciência ou que por ela se interessam nos seus estudos universitários (e não só). No fundo, reflectirem (mesmo) sobre qual o sentido da actividade que desempenham e associarem-se com outros no quadro da participação democrática para influenciar a orientação geral da sociedade.

\section{REFERÊNCIAS}

BECK, U. La société du risque: sur la voie d'une autre modernité. Paris: Flammarion, 2008.

BENTO, J. Por uma universidade anticonformista. Porto: U. Porto, 2014.

CACHAPUZ, A. Tecnociência, Poder e Democracia, in: SANTOS, W.; AULER, D. (Org.). CTS e Educação Científica, Brasília: UNB, 2011.

CACHAPUZ, A., Cultura científica y la defensa de la ciudadanía, Campo Abierto, 2016 (aceito para publicação).

CARO, P. O futuro do futuro, Público, 26 de Fevereiro de 2001.

ECO, H., Entrevista ao Jornal Diário de Notícias de 19 de Dezembro de 2015.

FORTI, A. O nascimento da Ciência Moderna, in: MAYOR, F.; FORTI, A. (Org.), Ciência e poder, Campinas, SP: Papirus, 1998.

FOUCAULT, M. Arqueologia do saber. Rio de Janeiro: Vozes, 1972.

\begin{tabular}{l|l|l|l|l|l|l} 
(C) Rev. Inter. Educ. Sup. & Campinas, SP & v.2 & n.2 & p.229-240 & maio/ago. 2016 & ISSN 2446-9424
\end{tabular} 
GASSET, J. Missão da universidade. Lisboa: Seara Nova, 1946.

GARCIA, M.; GEREZO, J.; LOPEZ, J. Ciencia, tecnología y sociedad. Madrid: Tecnos, 1996.

HARKER; D. Creating scientific controversies: uncertainty and bias in science and society. Cambridge: Cambridge Univ. Press. 2015.

JASANOFF, S. Science and democracy in Europe and USA. Princeton: Princeton Univ. Press, 2007.

JUDT, T. Um tratado sobre os nossos actuais descontentamentos. Lisboa: edições 70, 2010.

LIPOVETSKY, G. A felicidade paradoxal - ensaio sobre a sociedade de hiperconsumo. Lisboa: Edições 70, 2014.

LOSA, V. A Civilização do espectáculo. Lisboa: Quetzal, 2014.

MAYOR, F. Ciência e Poder: hoje e amanhã, in: MAYOR, F.; FORTI, A. (Org.). Ciência e poder. Campinas, SP: Papirus, 1998.

NEAVE, G. From Guardian to Overseer; Trends in Institutional Autonomy, Governance and Leadership, in: Políticas de ensino superior, Lisboa: CNE, 2008.

NERY; R. Uma cidadania partilhada. Público, 1 de Agosto de 2016, p. 24-26.

PEREIRA, P. Sobre a crise dos jornais. Público, 9 de Janeiro de 2016, p. 52.

PETERSEN, J. et al. STEM Education Coalition, annual report. Washington, DC, 2015.

PrAIA, J.; CACHAPUZ, A., Ciência, Tecnologia e Sociedade um Compromisso Ético,

Revista Ibero Americana de Ciência, Tecnologia y Sociedad, v.2, p.173-194, dez. 2005.

REIMÃO, C. A formação pedagógica dos professores do ensino superior. Lisboa: Colibri, 2001.

SANTOS, B. S. Introdução a uma ciência pós moderna. Porto: Afrontamento, 1989.

SANTOS, M.E., Cidadania, conhecimento, ciência e educação CTS: rumo a "novas" dimensões epistemológicas, Revista Ibero Americana de Ciência, Tecnologia y Sociedad, v. 2, 137-157, dez. 2005.

SCLOVE, R. Democracy and Technology. NY: Guilford Press, 1995.

SHAMOS, M. The myth of scientific literacy. NJ: Rutgers Univ. Press, 1995.

SOLBES, J. Los valores de la enseñanza de las ciencias. Alambique, n.22, p.97-108, 1999.

\begin{tabular}{l|l|l|l|l|l|l} 
(C) Rev. Inter. Educ. Sup. & Campinas, SP & v.2 & n.2 & p.229-240 & maio/ago. 2016 & ISSN 2446-9424
\end{tabular}


ZIMAN, J. A ciência na sociedade moderna. In: A CIÊNCIA tal qual se faz. Lisboa: Sá da Costa, 1999.

\footnotetext{
'Este trabalho é financiado por Fundos Nacionais através da FCT - Fundação para a Ciência e a Tecnologia no âmbito do projeto UID/CED/00194/2013.
} 